\title{
CUATRO SIGLOS DEL VIAJE DE LOS HERMANOS \\ NODAL A LA TIERRA DEL FUEGO (1618-1619)
}

MATEO MARTINIC B. ${ }^{a}$

En memoria del eminente botánico Edmundo Pisano Valdés (1920-1997)

\section{RESUMEN}

Este artículo tiene por objeto rememorar la que en su época fuera la más breve y feliz de las expediciones españolas al Nuevo Mundo, sin embargo de lo cual quizá ha sido la más olvidada por la posteridad: aquella que fuera puesta al mando del capitán Bartolomé García de Nodal y realizada por orden del rey Felipe III con el encargo de verificar el hallazgo holandés de 1616 referido a un nuevo paso para la navegación entre los mares del Norte y del Sur, y que tuvo ocurrencia entre 1618 y 1619 . Para ello se hace una relación sucinta sobre sus antecedentes, organización y el viaje marítimo propiamente tal, y se incluyen algunas consideraciones acerca de sus resultados apreciados desde distintos aspectos. En particular se hace referencia a la primera circunnavegación de la Tierra del Fuego y al significado de su principal hallazgo geográfico como fuera el descubrimiento de las islas Diego Ramírez. Este territorio insular es materia de una especial valoración como patrimonio natural excepcional por su posición geográfica extrema en el borde meridional de la plataforma continental americana.

PALABRAS CLAVE: Tierra del Fuego, Cabo de Hornos, islas Diego Ramírez, circunnavegación fueguina, naturaleza extrema, patrimonio natural.

\section{FOUR CENTURIES OF THE BROTHERS NODAL VOYAGE TO TIERRA DEL FUEGO (1618-1619)}

\section{ABSTRACT}

This article aims to reminisce what was the shortest and happiest of Spanish expeditions to the New World in its time, however, perhaps it has been the one most forgotten by posterity: the one that was put under the command of Captain Bartolomé García de Nodal and made by order of King Philip III with the order to verify the Dutch find of 1616 referred to a new passage for navigation between the

Profesor Emérito e Investigador, Centro de Estudios del Hombre Austral, Instituto de la Patagonia. Universidad de Magallanes, Punta Arenas. $>$ mateo.martinic@umag.cl 
seas of the North and South, and that occurred between 1618 and 1619. For this purpose a succinct relation on its antecedents, organization and the maritime trip itself, and some considerations about its results appreciated from different aspects are included. In particular, reference is made to the first circumnavigation of Tierra del Fuego and the significance of its main geographical finding, such as the discovery of the Diego Ramirez Islands. This insular territory is the subject of a special assessment as an exceptional natural heritage due to its extreme geographical position on the southern edge of the american continental shelf.

KEY WORDS: Tierra del Fuego, Cape Horn, Diego Ramírez Islands, fuegian circumnavigation, extreme Nature, natural patrimony.

\section{ANTECEDENTES DE LA EXPEDICIÓN}

El regreso a Holanda de Willem Schouten a mediados de 1617, quien un año antes había comandado el exitoso viaje al sur de América que había permitido comprobar más allá de cualquier duda el término geográfico meridional del continente americano y la existencia de un nuevo paso entre los océanos Atlántico y Pacífico, y la pronta difusión de tal noticia -que para la inmensa mayoría de la gente resultó sorprendentey que no demoró en divulgarse por toda Europa, conmocionaron a la monarquía española. Aunque, en verdad, la corte hispana poseía desde hacía mucho tiempo informaciones que daban cuenta de diferentes avistamientos casuales acerca de mar abierta hacia los $55^{\circ}$ de latitud, desde la memorable derivación de la nao San Lesmes en 1526, ocurridos a lo largo del siglo precedente en especial tras la incursión de Francis Drake en el Pacífico Sur en 1578, lo cierto es que la política del secreto puesta en práctica tanto por los ingleses como por los españoles había contribuido a mantener en duda la posibilidad de existencia de un segundo y más austral paso de mar entre los mares del Norte y del Sur al meridión del estrecho de Magallanes. Así, siquiera en apariencia, España siguió considerando a este último océano como un vastísimo espacio geográfico para su exclusivo uso y dominio. Pero la ficción así mantenida se vino definitivamente abajo tras el viaje de Schouten, sin embargo de cuya evidencia se creyó necesario confirmar el sorprendente hallazgo del término continental de un nuevo paso marítimo interoceánico franco a su vera, mediante una expedición propia que así lo

1 Las menciones a Lisboa y a los portugueses no debe sorprender pues desde 1580 las coronas de España comprobara y al fin lo ratificara.

Decidida la medida, el rey Felipe III encomendó al marino gallego Bartolomé García de Nodal, un capitán de experiencia probada, la responsabilidad de organizar una expedición para su cumplimiento. Se eligieron para el efecto dos buenos barcos ligeros y de apropiado diseño, de 80 toneladas cada uno, que se encontraron disponibles en el puerto de Lisboa. Si adquirir las naves y equiparlas para un viaje redondo que se estimó en diez meses fue cosa fácil y rápida, la recluta de las tripulaciones (80 hombres en total) resultó ser una empresa más ardua, pues no se contó con el número suficiente de voluntarios, de allí que fue menester contratar a la fuerza a la gente, todos portugueses ${ }^{1}$. Más eficaz fue la contratación de oficiales pues la plana incluyó a Gonzalo de Nodal, hermano de Bartolomé y con experiencia y foja de servicios tan relevante como la que aquél poseía, además de un bien calificado grupo de pilotos, comenzando con Diego Ramírez de Arellano, quien además era cosmógrafo de nota, al que se sumaron los flamencos Peter de Leetter (Pedro de Letre para los españoles), Jan de Witte (Juan Blanco igualmente) y Valentyn Janszoon o Janssen, entre otros pues para la expedición se contrataron en total ocho pilotos. De los nombrados Witte al parecer había navegado por el estrecho de Magallanes con Spilbergen (1614) y los otros lo habían hecho con Schouten y Le Maire. Se apreciaba en ellos tanto su experiencia náutica cuanto sus conocimientos de la geografía meridional, ... estos hombres son tan cuidadosos y puntillosos en el ejercicio de su profesión, que deben saber bastante de lo que otros han hallado, escribió sobre ellos

y Portugal se hallaban en manos del mismo monarca, situación que se mantendría hasta 1640 
Francisco de Tejada y Mendoza, Presidente de la Casa de Contratación de Sevilla, al recomendar su incorporación a la expedición ${ }^{2}$. Completados los preparativos, Bartolomé de Nodal se embarcó en la carabela Nuestra Señora de Atocha, nao capitana por tanto, y su hermano Gonzalo en la carabela Nuestra Señora del Buen Suceso, que zarparon del puerto de Lisboa el 27 de septiembre de 1618 con destino al meridión americano.

\section{RUMBO AL REMOTO SUR DE AMÉRICA}

Luego de un cruce atlántico sin mayores novedades el 15 de noviembre los barcos echaron sus anclas en la bahía de Río de Janeiro. Allí los Nodal se detuvieron para preparar a sus naves para el viaje austral previendo, como habría de ocurrir, mares y tiempos bravos, trabajos que demoraron un par de semanas. Zarparon de ese puerto el 1 de diciembre y el 7 de enero de 1619 arribaron a la ría de Deseado, paraje ya histórico en los viajes al estrecho de Magallanes como que a lo largo del siglo transcurrido desde la llegada del gran lusitano casi todos los capitanes que lo habían seguido en el rumbo meridional habían recalado en ese puerto del litoral patagónico, al que los Nodal apreciaron únicamente como fondeadero de circunstancia dada la escasez de recursos de agua potable y leña combustible.

Continuaron al sur y tras un fallido intento de entrar en la ría de San Julián prosiguieron recalando sucesivamente en los estuarios de los ríos Santa Cruz y Gallegos para su reconocimiento, arribando el 15 de enero al cabo de las Vírgenes y boca oriental del estrecho de Magallanes con idéntico propósito. Habiéndose avistado durante esta faena los restos de una nave en la costa interior de la actual punta Dungeness, Bartolomé de Nodal quiso cerciorarse sobre el hecho y envió una chalupa con gente en plan de investigación. Se advirtió que se trataba de un naufragio ya antiguo, con restos de maderamen y ferretería, además de huellas de presencia humana en el lugar, señal de acampamento de visitantes.

Se trataba, es claro, de los restos de la carabela Trinidad que en 1584 había sido varada por orden

2 Pablo J. Gallez, Valentín y sus dos bahías fueguinas, en Karukinka, 6, 17-31, Buenos Aires, 1973. La contratación de flamencos y holandeses en la expedición de que se trata de Pedro Sarmiento de Gamboa para facilitar su descarga, pero la maniobra había sido ejecutada de tan mala manera que hubo de darse por perdida a la nave al quedar la misma expuesta al castigo del mar. Extraídos los materiales y elementos posibles de utilizar en la faena de poblamiento en que ese capitán se encontraba empeñado por entonces (Ciudad del Nombre de Jesús), las partes del navío consideradas irrecuperables quedaron expuestas a la vista de otros navegantes posteriores que por allî pasaron, entre ellos el inglés Hawkins en 1593. Treinta y cinco años después lo que quedaba de ese barco todavía pudo parecer por su estado a los Nodal como algo de ocurrencia reciente, de allí que una de las razones para su inspección estuvo en la posibilidad de encontrar quizá algún sobreviviente de la nave siniestrada.

Reanudada la navegación el 18 de enero, el viaje pasó a su etapa más importante, la del reconocimiento (en verdad conocimiento para los españoles) de la costa oriental de la tierra meridional del Estrecho. De allí que el rumbo de las naves se ciñera lo más posible a la costa para identificar formas litorales y bahías que se hallaron con profusión como lo acreditan los topónimos asignados (canal de San Sebastián, pues tal se creyó a la bahía homónima; cabos de Peñas y de Santa Inés, punta de San Vicente, cabo de San Diego), hasta llegar el día 22 al excelente ancladero que se nombró bahía del Buen Suceso, hallazgo especialmente memorable también porque aquí la gente de la expedición tuvo el primer avistamiento y trabó la primera relación con los indígenas de la Tierra del Fuego nunca antes habida entre éstos y los europeos. Se trataba de una parcialidad sudoriental de los cazadores de cuya presencia Fernando de Magallanes y su gente habían observado humos y fuegos. Tras una breve y pacífica relación de que se trata más adelante, el viaje prosiguió a través de uno de los nuevos pasos que los españoles debían reconocer, el de Le Maire, al que se rebautizó como Estrecho de San Vicente, siempre en procura del cabo terminal de América que los holandeses habían llamado de Hoorn. Al fin llegaron a la meta propuesta al amanecer del martes 5 de febrero pudiendo observar a gusto el notorio peñón insular

debe entenderse en el contexto de la tregua entre España y las rebeldes provincias holandesas pactada en 1609 y que se extendería hasta 1621. 
cuya punta austral hace el cabo y, sobre la marcha, su redenominación como correspondía: cabo de San Ildefonso. Entonces pudo comprobarse la realidad geográfica del término continental y de la inmensidad oceánica que lo baña.

Como se imponía, se hizo el registro de la posición en que se hallaban las naves:...se tomó el Sol en el Astrolabio 40. grados y de declinación 15. grados y cincuenta minutos, que hacen 56 menos un tercio ${ }^{3}$. Con esta observación y registro se había cumplido lo principal de la comisión encomendada a Bartolomé García de Nodal. El hallazgo holandés de tres años antes quedaba comprobado y ratificado: la tierra del sur del estrecho de Magallanes era una isla (tal como lo había preanunciado Drake en 1578) y al sur de su cabo terminal únicamente había mar libre, un nuevo paso franco para navegar.

Los seis días que siguieron se pasaron sobre mar brava por los vientos y el oleaje en reconocimientos y descubrimientos menores en torno al cabo de San Ildefonso. Y a la jornada siguiente, martes 12 de febrero luego de haber derivado hacia el sudoeste del cabo amanecieron en proximidad de unas islas desconocidas, pequeñas y remotas perdidas en el inmenso y proceloso mar austral y que recibieron en conjunto el nombre del excelente piloto mayor, Diego Ramírez de Arellano. Con este hallazgo geográfico se hizo la mayor y principal contribución de la expedición hispana de 1618-19, que la posteridad ha valorado sin retaceo y que cimentaría el prestigio de los hermanos Nodal en la historia náutica universal ${ }^{4}$. Esta etapa final de la primera parte del viaje se desarrolló, importa consignarlo, en medio de un zarandeo que no dio tregua a los buques ni descanso a sus tripulaciones. Fueron singladuras absolutamente ingratas pues...todos estos días fueron muchas tormentas, aguaceros furiosos, con mucho frío y nieve, como consigna la Relación ${ }^{5}$. Fue esa la primera experiencia brava así registrada que los

3 Relación del Viage que por orden de Su Magestad $y$ acuerdo de el Real Consejo de Indias, hicieron los capitanes Bartholomé García de Nodal y Gonzalo de Nodal, hermanos, naturales de Pontevedra, al descubrimiento del estrecho nuevo de San Vicente, que hoy es nombrado de Maire, y al reconocimiento del de Magallanes. Madrid, 1621, p. 78.

4 Sirva como ejemplo, para el caso, la opinión del historiador inglés James Burney: The Discovery of these Isles is the navegantes del porvenir que por allí pasarían, sufrirían una y otra vez, afirmando de esa manera una fama siniestra para ese pasaje marítimo en las rutas del mundo.

\section{EL TORNAVIAJE Y LA CIRCUNNAVEGACIÓN FUEGUINA}

El viaje de regreso se hizo procurando escapar de aquella mar embravecida del Cabo en demanda de la boca occidental del estrecho de Magallanes pues Bartolomé Nodal quería seguirlo para completar la circunnavegación de la tierra meridional del mismo. El objetivo se logró el día 25 de febrero cuando las naves pudieron ingresar a la vista de los islotes Evangelistas...que están de la parte del Norte; quando entramos para dentro, por donde quedamos satisfechos era el Estrecho, huvo a la entrada mucha corriente para fuera, cargó el Viento Oeste y Oes-Sudueste, con aguaceros, que nos metió dentro, dando muchas gracias a Dios que nos hizo tantas y señaladas mercedes: dimos fondo ya tarde, aunque de día a dos leguas del Cabo Deseado, para el otro día hacer las observaciones y para descansar, que todos veníamos muy trabajados de la Mar y del mal tiempo que se tuvo después que se partió del Estrecho Nuevo [San Vicente] 6 , resumiría el jefe expedicionario en su relación, a completa cabalidad, las singladuras más decisivas y duras del largo viaje.

Estrecho adentro los expedicionarios prosiguieron con tranquilidad los registros $y$ observaciones y el 28 , último día del mes, las naves anclaron en el puerto de la costa septentrional del sector central, que se bautizó como de San Joseph y que se describió así: Viernes primero de Marzo al amanecer, entramos dentro de una Ensenada, que hay en esta Bahía, que es como Rio muerto, para dár monte, y limpiar, y ensebar, tomar agua y leña, que todo hay muy bastantemente: luego

most remarkable circumstance which ocurred in the voyage of the Nodales. They continued Turind a Century and a half to be the most Southern Known marked on the charts. (A chronological history of the discoveries in the South Sea or Pacific Ocean; ilustrated with charts. London, 1806. Vol. 2, chap. 21 pp. 460-461).

Op. Cit., p. 84.

Id. p. 88. 
en aquella mañana que se entró, se encallaron los Navios, y aunque no descubrieron mucho, ensebamos lo mejor que se pudo ${ }^{7}$. Era ese, es tiempo de decirlo, el famoso puerto de las Sardinas conocido y bautizado un siglo antes por Fernando de Magallanes durante su memorable travesía descubridora y que había acogido también a los holandeses de Simón de Cordes en su obligada y penosa estadía invernal de cuatro meses en 1599.

Allí, otra vez rememorando al gran luso, las naves hicieron aguada, se extrajo leña combustible, se calafatearon los cascos y se recogieron mariscos hasta hartarse (se trajo para toda la Quaresma en escabeche), ratificándose así, nuevamente, la bondad de aquel histórico tenedero. Alli también los expedicionarios encontraron viviendas de los indígenas canoeros que desde siempre merodeaban por esos parajes, aunque no vieron ser humano alguno.

Las siguientes recaladas se hicieron en la bahía de San Nicolás (5 de marzo) donde se realizaron más reconocimientos y nuevos registros del sol, y en otros sitios de la costa occidental del Estrecho cuya amplitud en esa parte (Paso Ancho) llamó su atención, llegando el 8 junto a las islas de los Pingüinos. Allí se cazó una buena cantidad de esas aves para renovar y variar la provisión alimentaria de los buques, faena en la que se estuvo hasta el día siguiente. Estrecho avante el 11, pasada la Primera Angostura fondearon las carabelas sobre la costa del sur del gran saco oriental y al día siguiente cruzaron hacia la parte del norte (costa del cabo Posesión) en donde se observaron algunos indios patagones, uno de los cuales hizo señas llamando la atención de los marinos. Visto eso, Bartolomé Nodal llegó a pensar que podía tratarse de alguno de los sobrevivientes que se habían salvado del navío siniestrado observado a la venida en la parte interior de la costa de Dungeness y en consecuencia ordenó que fuera a tierra una partida para tratar con esa gente, aunque, si se trataba de indígenas, se mantuvieran lejos de la orilla por precaución. Los patagones (aónikenk) andaban en son de paz $y$ pese al esfuerzo de los religiosos embarcados en la chalupa fue imposible entenderse con ellos. Hecho eso, el viaje se reanudó a la vista de la

Ibid. p. 94.

Ibid. p. 109

Los Nodal fueron los sextos navegantes en pasar por el costa septentrional y los buques fueron a fondear en el mismo sitio a las espaldas del cabo Vírgenes donde se hallaban los restos náufragos observados en enero. Allí, según la Relación, En la playa hallamos rastro de gente y de ganado vacuno de pata hendida [guanacos] y de perros; en lo alto del Monte hicieron los Indios fuego, con grande humo, que luego se apagó: volvimos a sacar de la Nao perdida que hallamos la primera vez en la playa algunas cabillas de hierro ${ }^{8}$.

Salieron el 13 de marzo tras un nuevo registro del sol y tomaron el rumbo norte para el regreso a Europa. Con el recorrido fretano los Nodal habían completado la primera circunnavegación de la Tierra del Fuego, hazaña náutica ciertamente que por ese solo mérito calificaría su expedición para la historia9.

En una navegación tranquila y sin incidencias de nota y tras una escala en la colonia portuguesa de Pernambuco (1 de mayo), zarparon definitivamente el día 14. El cruce atlántico fue igualmente tranquilo salvo un ominoso encuentro con un corsario francés del que salieron bien librados los españoles, el domingo 7 de julio se vio tierra europea en el cabo San Vicente, punto en el que el capitán Gonzalo de Nodal desembarcó para dar cuenta del viaje al rey Felipe III que se hallaba por entonces en Lisboa. El 8 los buques se hicieron a la vela con rumbo a San Lúcar, antepuerto sevillano al que se arribó al día siguiente, dando Bartolomé García de Nodal por acabado el viaje a Dios gracias y a la Virgen de Atocha y del Buen Suceso, oración con la que se dio término, también, a su Relación.

De ese modo concluyó el que, se reitera, pudo como puede ser considerado el viaje más breve y feliz de una comisión exploratoria española al Nuevo Mundo. Lo primero, porque se empleó en el mismo menos tiempo que el previsto (nueve meses y diez días), algo prácticamente imposible en la época; y lo segundo porque no hubo en su transcurso desgracias que lamentar y porque no falleció tripulante alguno, todo ello gracias a la eficaz coordinación lograda entre el responsable y eficiente comando y la buena faena de los competentes pilotos; porque se cumplieron los objetivos encomendados $y$, por fin, porque con el hallazgo

Estrecho de oeste a este tras Hernando Gallego (1553), Juan Ladrillero (1558), John Winter (1579), Pedro Sarmiento de Gamboa (1580) y Sebald de Weerdt (1600). 
de las islas Diego Ramírez y la circunnavegación fueguina inclusive se sobrepasaron.

Sin embargo del contento con que se recibió a los Nodal de regreso y de los agradecimientos que ellos, Ramírez de Arellano y otros oficiales recibieron, la posteridad si no olvidaría, a lo menos disminuiría los méritos del viaje dejándolo en la penumbra de la historia, involuntariamente por cierto. En busca de una justificación para el aserto, ella la encontramos en primer término en la ratificación del hallazgo holandés de 1616 referido especialmente al nuevo paso interoceánico austral, en la consiguiente pérdida de importancia estratégica del estrecho de Magallanes como única vía de navegación hacia la costa occidental de Sudamérica y otras partes del Pacífico y, por ende, en la pérdida de la hegemonía hispana sobre el vastísimo Mar del Sur y sobre el control de su acceso sudoriental. Definitivamente, a partir de entonces, el océano Pacífico dejaría de ser "el lago español" después de las expediciones de 1615-16 y 161819. En segundo término, que ante esa realidad, la otrora poderosa potencia hispana, lo era mucho, muchísimo menos, corriendo la segunda década del siglo XVII.

Las fisuras que resquebrajaban el imperio se advertían por todas partes: en Europa, la pérdida definitiva de los Países Bajos, la inacabable tirantez con Francia e Inglaterra, los graves problemas en Cataluña y en Nápoles, las guerras religiosas en el centro de Europa, vinculada como se hallaba la monarquía española con la casa imperial de Habsburgo que allí regía y que se prolongarían por treinta años hasta el medio siglo XVII, la descomposición del vasto imperio colonial portugués que sufría los embates de holandeses e ingleses, en fin, todo ello y más, basta para entender la dificilísima coyuntura en la que se hallaba la España de Felipe III, expresada al fin en pérdida de prestigio, de poder y hasta de capacidad de reacción. Nada podía hacerse, ni se hizo, como no fuera enfrentar de diferente y nunca completamente satisfactoria manera tantos asuntos y problemas, y esperar casi insensiblemente el curso de la decadencia que avanzaría según lo hacía el siglo hasta desembocar en el colapso de 1700. En ese tráfago involuntario se perdería virtualmente la memoria de muchos sucesos americanos, entre ellos la afortunada expedición de los hermanos Bartolomé y Gonzalo de Nodal a la Tierra del Fuego en 1618-19.

\section{TRASCENDENCIA DE LA EXPEDICIÓN DE LOS NODAL}

El resultado de tan venturoso viaje puede ser considerado bajo cuatro aspectos principales: en primer lugar, el geográfico; en segundo y como natural consecuencia del anterior, el cartográfico; en tercero, el etnográfico y por fin, el correspondiente a la jurisdicción territorial del Reino de Chile. En cuanto al primero y teniendo presente que el objetivo fundamental de la expedición de los hermanos Nodal era el de verificar el hallazgo holandés precedente de 1616, esto es la realidad de un paso franco interoceánico al sur de la Tierra del Fuego, tal circunstancia se vio confirmada con su propia navegación de nororiente a surponiente con el cabo de Hornos a la vista. Pero la derivación que siguió a este curso permitió aportar un nuevo hallazgo geográfico que resultaría ser el punto austral más extremo del continente americano, sin embargo de su posición distante del conjunto insular litoral que así lo configura, como fue el descubrimiento del pequeño archipiélago que recibió el nombre del piloto mayor de la expedición, Diego Ramírez de Arellano, situado lejos de la masa continental cuya plataforma comparte, a unas 60 millas del cabo de Hornos.

Conozcamos la parte pertinente de la Relación de Nodal: Martes 12 de Febrero, día de Carnestolendas, amanecimos á la Mar del Cabo de San Ildefonso; saltó el Viento á Loesnoroeste, la vuelta del Sudueste, anochecimos cosa de dos leguas de la Isla de Diego Ramírez, que está Nordeste y Sudueste con el Cabo de San Ildefonso: volviose a sondar 50 ó 55 brazas, y limpio ${ }^{10}$.

Ya está dicho, en realidad lo encontrado era más que una isla, todo un pequeño archipiélago que se alarga en dirección nornoroeste a sursureste por unos 12 kilómetros y que está conformado por dos grupos de islotes, rocas y arrecifes separados entre sí por un espacio de mar de unas dos millas. El más septentrional es un conjunto de rocas de escasa superficie y baja altura; el grupo meridional

$10 \quad$ Ibid. pp. 83 y 84. 
incluye a dos islas de mayor tamaño, denominadas Bartolomé y Gonzalo, separadas entre sí por el canal Nodales de aproximadamente un cuarto de milla de ancho. Aquélla mide unos 2.500 metros de largo por 500 de ancho y ésta, unos 1.600 metros de longitud por unos 400 metros en su sección más ancha; la altura máxima se encuentra en la isla Gonzalo y alcanza a unos 130 metros, en tanto que Bartolomé tiene unos 90 metros en su punto más elevado. Ambas son de orografía caracterizada por formas abruptas y escarpadas menos acusadas hacia el este. El grupo se completa con islotes menores, rocas y arrecifes. Para el Instituto Hidrográfico de la Armada de Chile la coordenada de situación del archipiélago es 56 $30^{\prime} 44^{\prime \prime}$ sur y 68 $42^{\prime} 48^{\prime \prime}$ oeste $^{11}$. Por su posición aislada y expuesta en la inmensidad del mar de Drake sufren el castigo permanente del oleaje y de los elementos de un clima habitualmente severo y variable que dificulta su accesibilidad. Exiguo territorialmente, la importancia del archipiélago radica en su situación latitudinal extrema en el borde mismo de la plataforma continental americana, en tanto que relicto de antiquísimas formas geológicas, que alberga un ecosistema natural propio y por ello excepcional, según se considera más adelante.

El segundo aspecto que permite valorar el viaje de los Nodal corresponde a la cartografía generada por o basada en el mismo. Sin embargo, antes de abordar el punto debe aceptarse que la expedición en sus preparativos hubo de considerar el conocimiento de uno o más planos que permitieran informarse siquiera de modo aproximado sobre el ámbito geográfico que se iba a recorrer, en especial al sur del estrecho de Magallanes. Pero tal necesidad apenas si pudo satisfacerse pues prácticamente la totalidad de las cartas geográficas en uso en la época, daban cuenta de una configuración territorial que se ceñía a la tradición de un siglo, esto es, al entendimiento de haber continuidad terrestre desde el litoral del estrecho de Magallanes hasta un indefinido límite meridional -la Terra Australis por ello calificada de Incognita o Nundum Cognita-. La excepción,

11 Véase la carta 1315, Atlas Hidrográfico de Chile, edición de 1974.

12 Véase nuestro artículo "Drake y la insularidad fueguina" (Anales del Instituto de la Patagonia, serie Ciencias Humanas, 26, 5-22, 1998). como se sabe estuvo conformada por contadas piezas que daban cuenta del avistamiento hecho por Francis Drake en 1578 acerca de la probable insularidad fueguina ${ }^{12}$. Se desconoce si los cartógrafos y pilotos de la Casa de Contratación de Sevilla conocían ese raro cuanto sugerente material documental y si, de haberlo conocido, sobre la credibilidad que le prestaban para informar a la futura expedición de los hermanos Nodal. Pero sobre lo que no debiera caber duda es que tanto estos capitanes como aquellos funcionarios debieron conocer los primeros planos que ilustraron el hallazgo holandés del cabo de Hoorn comenzando por el preliminar elaborado por Willem Schouten y que se difundió conjuntamente con las noticias iniciales de su expedición, y siguiendo con otras dos piezas del género que se sabe que circularon o inclusive que fueron realizadas en España hacia 1617-18 por dos de los pilotos flamencos que posteriormente se incorporaron a la expedición de los Nodal, Peter de Leetter y Jan de Witte $e^{13}$. Más que mapas acabados parecían ser esquicios preliminares con la información esencial adquirida por sus presuntos autores tras su participación en los viajes de Schouten-Le Maire, en un caso, y de Georg Spilbergen en el otro, y que debió ser especialmente valorada como para que un tercer cartógrafo, esta vez el español Antonio Moreno, de quien nada se sabe, elaborara su propio mapa que llamó Carta de la Región Magallánica, Tierra del Fuego y Estrecho de Le Maire, que se conserva en el Departamento de Manuscritos de la Biblioteca Nacional de Madrid (Fig. 1).

Estas tres piezas comparten un muy semejante dibujo del contorno geográfico sudpatagónico, que es la materia de la representación, y que en la parte austral donde radica su novedad incluye una escasa toponimia originada en el viaje de Schouten-Le Maire, características que permiten pensar que su inspiración estuvo en este memorable periplo.

$\mathrm{Y}$ tornando al punto principal, el fruto más notable del viaje de los Nodal es el famoso mapa manuscrito y coloreado construido por el piloto Diego Ramírez de Arellano, cuyo título

13 Véase Atlas of Cape Horn. The Cartography of Southern South America 1500-1725 (Pieter Kroon, Ed. General, Thoth Publishers Bussum, 2016), pp. 114, 116 y 119 123. 


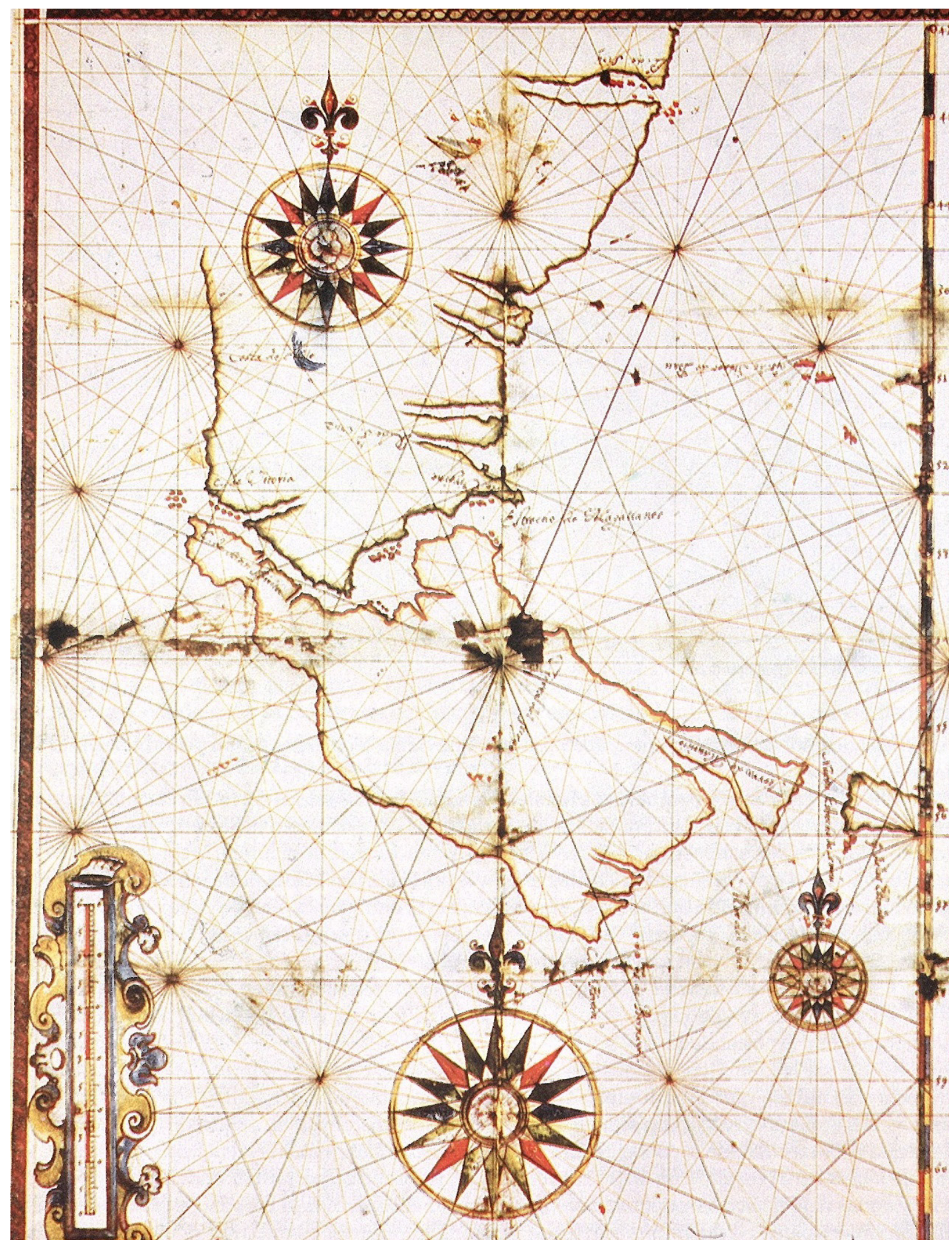

Fig. 1. Carta de la región Magallánica, Tierra del Fuego y estrecho de Lemaire. Antonio Moreno (1618). 
lo describe como Quarteroncillo fabricado del Reconocimiento que de los estrechos de Magallanes y $\mathrm{S}$. Vicente se hizo por orden de su magestad y junta de guerra de indias el año 1619, recorrido echo por el capitán Diego Ramírez de Arellano, natural de Xativa, cosmógrafo y piloto maior por su magestad y criado del principe Filiberto (Fig. 2). En esta hermosa pieza que igualmente se conserva en la Biblioteca Nacional de Madrid, salta de inmediato a la vista el diferente trazado figurativo del bulto terrestre de la región meridional americana entre los grados $46^{\circ}$ y $56^{\circ}$ de latitud, con aquel común que muestran las piezas precedentemente mencionadas.

Sus rasgos litorales caracterizadores son los que corresponden a la parte sudoccidental de Patagonia y a la isla de Tierra del Fuego. En la primera el trazado de Ramírez de Arellano ignora y omite la noción del extenso archipiélago patagónico (sobre el que en España se poseía pleno conocimiento desde mediados del siglo XVI) y en su reemplazo muestra una costa más o menos pareja y continua con algunas penetraciones, en especial una muy profunda continente adentro los $49^{\circ} 30^{\prime}$ y los $52^{\circ}$ de latitud donde el único topónimo es ancón sin salida, debido, bien se sabe, al piloto Juan Ladrillero durante su búsqueda de la entrada occidental del estrecho de Magallanes (1557). El islario omitido está apenas figurado por una cadena de pequeñas islas que dan continuidad secundaria a la costa exterior. Este mapa sirvió de modelo en este particular a otras piezas elaboradas a lo largo del siglo XVII, entre ellas el de Pedro Teixeira (1621), el de Antonio de Vea (1676) y otros de autores desconocidos de hacia 1660-65 y 1690, todos manuscritos y conservados en el repositorio mencionado y en el Museo Naval de Madrid.

En la Tierra del Fuego, el mapa que se comenta reemplaza su denominación geográfica ya afirmada por la tradición de un siglo por el de Isla de Xativa, la comarca natal del autor, y la presenta como una masa territorial compacta, alongada y

14 De escarpín, zapatilla alargada y puntiaguda de uso elegante en el medievo tardío.

15 El viaje de Schouten y Le Maire dio origen a una copiosa cartografía manuscrita especialmente impresa a lo largo del siglo XVII, principalmente en Holanda, Francia e Inglaterra, donde radicaron los grandes centros productores del ramo. Esa cartografía incluye estilísticamente dos representaciones del bulto territorial, uno, en el que la Tierra del Fuego exageradamente enangostada hacia el sudeste, asumiendo una forma que hemos denominado "escarpinada" ${ }^{4}$, con una costa sudoccidental que corre con ligera curvatura desde el cabo Pilar hasta el de Hornos. Esta versión que debe considerarse como exclusivamente hispana fue seguida por los autores precedentemente mencionados ${ }^{15}$. El mapa incluye un trazado especial (línea segmentada) que señala el rumbo seguido y las recaladas practicadas por las naves de la expedición lo que explica el conocimiento litoral adquirido, hecho confirmado por la toponimia asignada.

La pieza completa su atractiva presentación con loxodromias, rosas de los vientos y un par de cartelas (Fig. 2).

La otra pieza cartográfica derivada del viaje de los Nodal es la titulada Reconocimiento de los Estrechos de Magallanes y San Vicente mandado hazer por Su Magestad en el Real Consejo de Indias, es obra del maestro cartógrafo portugués Pedro Teixeira Ealbernas y fue ejecutada en 1621. Manuscrita y bellamente iluminada está evidentemente inspirada en el mapa de Ramírez de Arellano, pues sin ser una copia exacta es muy semejante al mismo en su trazado litoral salvo detalles mínimos que las diferencian. Ambas piezas se complementan en materia de topónimos litorales, en el trazado del "canal" o entrada de San Sebastián, que en la de Teixeira se muestra como una vía que une el Estrecho con el Mar del Norte mientras que en la de Ramírez tal condición sólo se insinúa por sus entradas este y oeste. Por fin en el mapa del autor portugués la Tierra del Fuego aparece innominada y únicamente se consigna en su interior la palabra Isla. Pero donde la diferencia entre ambos mapas es visualmente notoria es en la representación ornamental de montañas en el interior territorial y en los litoral- es sudoriental, sudoccidental y sur que se aprecia en el mapa de Teixeira, mientras que en la del piloto hispano ambos sectores permanecen en blanco tanto en Patagonia como en la Tierra del Fuego.

\footnotetext{
aparece como un cuerpo geográfico compacto de cinco caras litorales, pero con una determinante prolongación meridional originada en el mapa de Schouten (1617). El otro, es una forma intermedia entre la precedentemente descrita y aquella diseñada por Ramírez de Arellano, más cercana a la realidad geográfica y que la evolución cartográfica consagraría (véase nuestra Cartografía Magallánica citada, p. 96 y siguientes).
} 


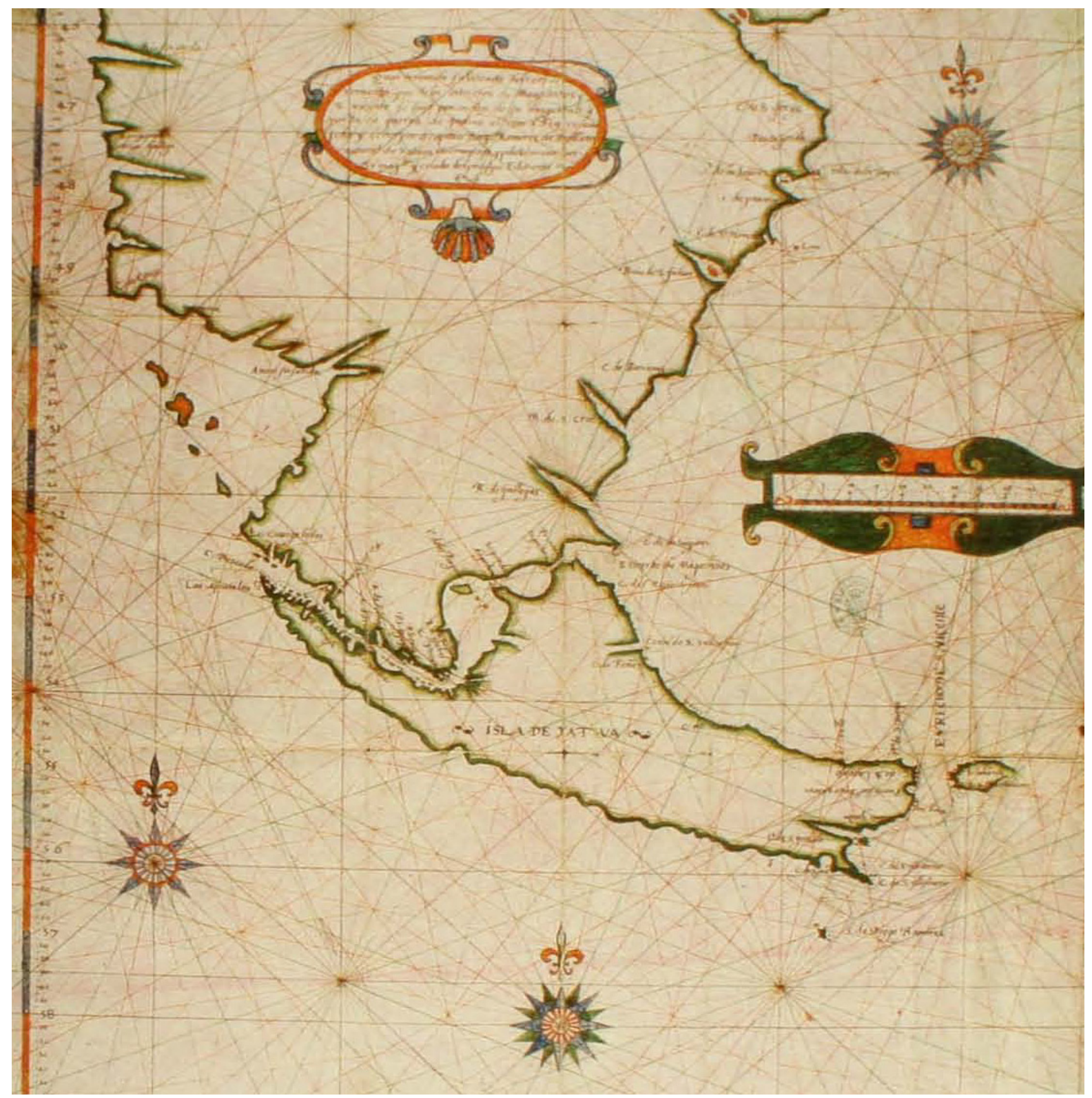

Fig. 2. Quarteroncillo fabricado del Reconocimiento que de los estrechos de Magallanes y S. Vicente se hizo por orden de su magestad y junta de guerra de indias, etc. Diego Ramírez de Arellano (1619).

La ornamentación de la pieza en descripción se completa como en la anterior con rosas de los vientos y loxodromias, a las que aquí se añade la representación de las carabelas que integraron la memorable expedición (Fig. 3).

Para la etnografía austral, recordando el tercer aspecto de los mencionados en la valoración hecha precedentemente, el viaje de los hermanos
Nodal ha conformado y conforma la primera, fidedigna y valiosa información testimonial sobre los cazadores recolectores que habitaron la Tierra del Fuego (isla grande), con seguridad sobre la parcialidad oriental de la etnia sélknam, esto es el grupo haush. Por lo mismo ha sido difundida y afamada entre los especialistas y en el ambiente académico en general, teniéndosela de una calidad 
semejante -y aun superior en lo descriptivo- a la tan famosa de Antonio Pigafetta acerca de los patagones (aónikenk) observados en San Julián durante la invernada de la expedición de Fernando de Magallanes en 1520. Tal valoración que compartimos nos exime de mayor consideración acerca del memorable encuentro entre europeos y fueguinos en la bahía del Buen Suceso en enero de 1619.

La Relación del viaje en esta materia aporta, además, las breves pero interesantes noticias sobre los kawéskar del occidente del Estrecho (puerto San Joseph) y los aónikenk de la costa de Posesión, referencias todas que ponen en evidencia que la incomunicación verbal entre foráneos y aborígenes no constituyó per se una razón de conflicto y que, pese a ello, la buena índole de los naturales pudo facilitar esos efímeros primeros contactos interculturales.

Por fin el cuarto aspecto que se considera para entender la trascendencia de la expedición de los hermanos Nodal en 1618-19 se refiere a la jurisdicción territorial del Reino de Chile, al acotarla claramente por el extremo meridional con el hallazgo de las islas Diego Ramírez. Las autoridades y la gente informada de la época no obstante ello parece haber dado escasa importancia a tal hallazgo geográfico vista quizá su pequeñez aunque sí su significado como la tierra más meridional hasta entonces y por otro siglo y medio más conocida en el planeta. En prueba señalamos que el historiador más famoso de su época, el jesuita Alonso de Ovalle no lo menciona en su clásica obra Histórica Relación del Reyno de Chile (1646) al ofrecer su descripción pormenorizada de "las islas del Reyno de Chile" (Cap. I, Libro II), sin embargo de reconocer entre sus fuentes de información escritos holandeses de la tercera década de esa misma centuria que hacen referencia a la expedición de los hermanos Nodal. Pero esa omisión quedó salvada a nuestro juicio al incluirse la representación de ese descubrimiento en su mapa TABVLA GEOGRAPHICA REGNI

16 Únicamente la primera de las cuatro versiones que se conocen de esta interesante pieza cartográfica, conocida como "Mapa grande" y de la que sólo se sabe de dos ejemplares (uno en la Biblioteca Nacional de París y otro en la John Carter Brown Library, Providence, EE. UU. de América), incluye la mención y representación de las islas Diego Ramírez, no así las otras tres que se conocen del
CHILE que acompañó a la edición original del libro (mapa grande) hecha en Roma en el año mencionado ${ }^{16}$.

El siguiente autor, el también jesuita Diego de Rosales que publicó algunas décadas después su propia importante obra (Historia General del Reyno de Chile. Flandes Indiano, Valparaíso 1877), menciona el hecho diciendo... Subieron arrojados de las borrascas hasta 63 grados en 57 y 20 minutos. Descubrieron una grande isla que en memoria de su cosmógrafo la apellidaron de Diego Ramírez y en 56 grados y 22 minutos otros islotes encapotados de nieve ${ }^{17}$.

Esta suerte de conducta ambigua en la referencia que interesa puede advertirse en otras obras y mapas españoles de los siglos XVII y XVIII, en especial en el bien conocido trabajo del afamado geógrafo Juan de la Cruz Cano y Olmedilla, Mapa Geographico de la America Meridional (Madrid, 1775), sin duda la mejor y más informada pieza geográfica acerca de los dominios sudamericanos del Imperio Español, mapa que en lo que interesa incluye inclusive por partida doble la representación de que se trata, situándola tanto al suroeste como al noroeste del cabo de Hornos. Importa señalar que en los mapas de los siglos mencionados elaborados fuera de España, en Holanda, Francia e Inglaterra principalmente, invariablemente se incluyó a las islas Diego Ramírez en la zona terminal del continente dándose a entender implícitamente su reconocimiento como de jurisdicción española por razón de proximidad a otras partes meridionales de América previamente conocidas y reclamadas por España a partir del viaje descubridor de Fernando de Magallanes, circunstancia ratificada por las decisiones político-administrativas referidas en particular al Reino de Chile de los años 15541555 y 1680.

La independencia de Chile del dominio hispano en 1818 no pareció alterar esa ambigua situación de omisión documental descriptiva y de representación cartográfica de la que otra prueba es el artículo pertinente del Reglamento

mismo mapa (Cfr. nuestro artículo "Rarezas cartográficas: I. Las cuatro versiones del Mapa de Chile del Padre Alonso de Ovalle. II. El curioso Mapa de la Región Magallánica de Francisco de Seixas y Lovera (1690)". (Boletín de la Academia Chilena de la Historia, 107, 385-400, Santiago, 1997).

17 Op. Cit. p. 68. 


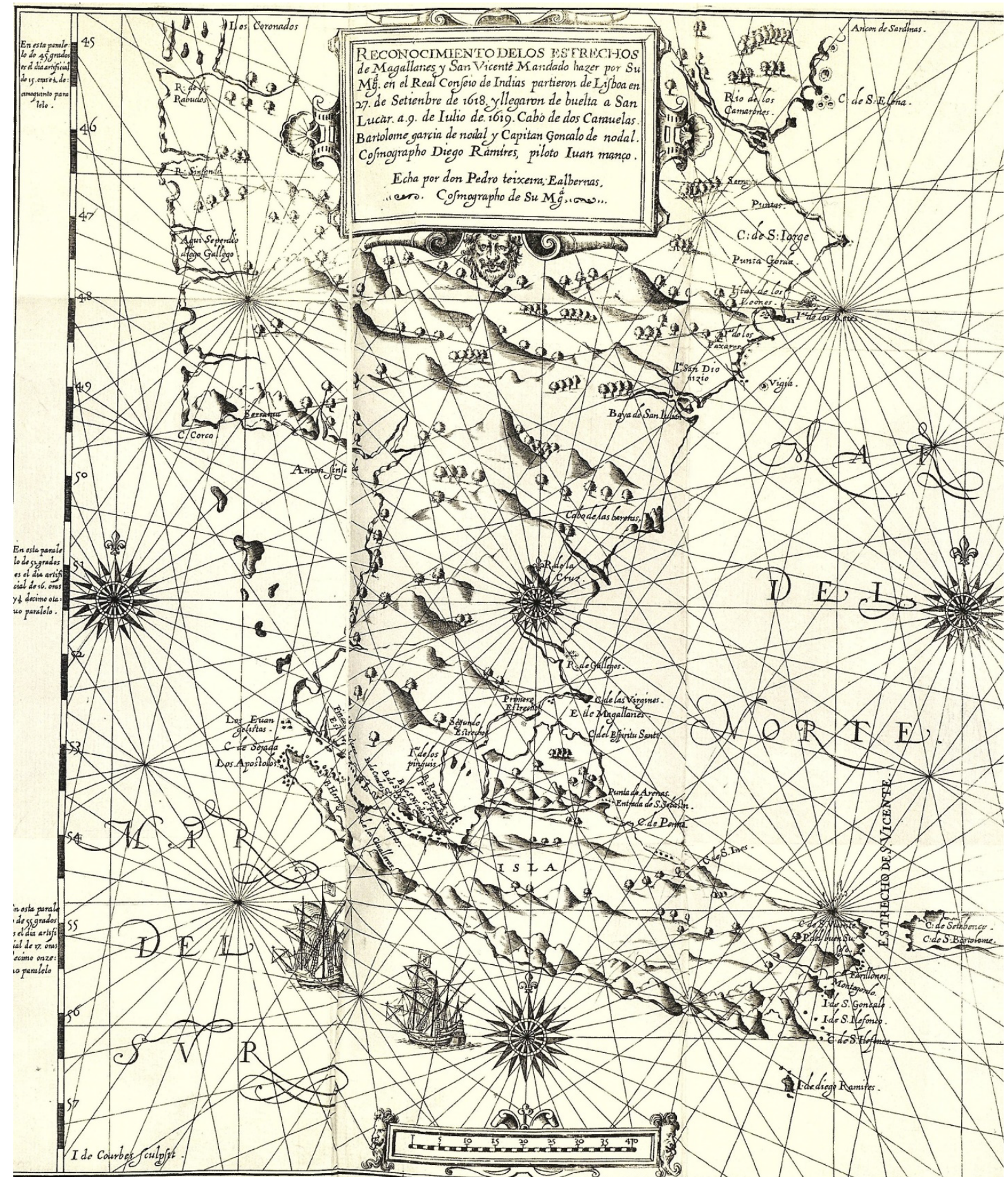

Fig. 3. Reconocimiento de los estrechos de Magallanes y San Vicente mandado a hazer por Su Magestad en el Real Consejo de Indias, etc. Pedro Teixeira Ealbernas (1621). 
Constitucional de 1822 que señala los términos jurisdiccionales del nuevo Estado, en el que en lo que se refiere a la parte austral se explicita que la misma está definida por el Cabo de Hornos como punto meridional extremo de la República ${ }^{18}$. Pero entonces ni después nadie dudó de la pertenencia a Chile de las remotas y pequeñas islas de Diego Ramírez dada su condición geográfica de proximidad o adyacencia al territorio mayor que lo integraba. Esa cabal comprensión se reflejó en el primer mapa oficial de la República de Chile, construido por el naturalista y geógrafo francés Claudio Gay por encargo del gobierno nacional y, como tal, pieza integrante de su bien conocida Historia Física y Política de la República de Chile (París 1856, en específico la carta "Estrecho de Magallanes" incluida en el Album de Viage por la República de Chile).

En ese predicamento se continuó el resto del siglo XIX, hasta sus postrimerías, época para la que ya era de dominio común la noción de riqueza de animales de piel fina en tan remoto dominio insular, cuando precisamente tal conocimiento sirvió de fundamento para diversas opiniones y acciones administrativas expresivas de preocupación por las actividades cinegéticas de embarcaciones de bandera extranjera en Diego Ramírez y otras islas del extremo austral de Chile y, por ende, para afirmar la jurisdicción nacional sobre las mismas.

Este aspecto justifica una mención especial sobre la materia. La presencia de pinnípedos (mamíferos anfibios) de piel fina de los que el más afamado es el llamado "lobo de dos pelos" (Arctocephalus australis) en los distritos litorales de la Patagonia occidental y la Tierra del Fuego, así como en las islas Falkland, Orcadas, Shetland y Península Antártica, fue conocida y difundida paulatinamente en losámbitos marítimo-mercantiles de Gran Bretaña y Estados Unidos a partir del quinto final del siglo XVIII, época en que aumentó notoriamente la demanda mundial por productos tales como aceites y grasas de ballenas y otros

18 Interesa para el caso recordar la parte pertinente de la Declaración de la Independencia de Chile firmada por Bernardo O'Higgins, Director Supremo del Estado, el $1^{\circ}$ de enero de 1818 en Talcahuano y proclamada el 12 de febrero siguiente en la ciudad de Talca:...se hace saber a la gran confederación del género humano que el territorio continental de Chile y sus islas adyacentes mamíferos marinos inicialmente y luego de cueros y pieles finas, circunstancia que motivó la presencia recurrente de expediciones de caza (balleneros, foqueros o loberos) en una secuencia geográfica que las condujo desde las costas sudorientales de la Patagonia, a las islas atlánticas y subantárticas, al propio continente polar (península Antártica) y, de paso o al retorno de las mismas, al sur de la Tierra del Fuego y a las costas occidentales de la misma y de la Patagonia. La caza se desarrolló en su fase más intensiva desde los inicios del siglo XIX hasta fines de los años de 1820 aproximadamente, tanto que redujo el número de animales de las especies más demandadas en algunos casos hasta su virtual extinción.

Entre los últimos territorios mencionados se encontraban preferentemente las actuales islas australes y sudoccidentales de Chile. De aquéllas hacia la tercera década del siglo XIX ya gozaban de fama en el ambiente cinegético de los puertos de Nueva Inglaterra (Boston, New London, Stonington, Mystic, entre otros varios) las denominadas "Islas Diego" o simplemente "las Diegos", como lo afirma con propiedad Briton Cooper Busch, historiador norteamericano contemporáneo especializado en las actividades marítimas, en su obra ya clásica ${ }^{19}$, al dar cuenta de una faena de naves de su bandera que era especialmente intensa en los años 20 del siglo y que abarcaba sectorialmente desde la isla de los Estados hasta el grupo rocoso de Los Evangelistas (boca occidental del estrecho de Magallanes) e isla Madre de Dios y vecindad, incluyendo las islas Ildefonso, Negra y Furias en la costa fueguina del Pacífico, espacio en el que se encuentran las islas Diego Ramírez. Para este lugar Briton C. Busch menciona los nombres de schooners procedentes de los puertos de New London y Stonington que fueron los más activos en las faenas del género, citando en específico al Penguin, armado en el primero de los sitios nombrados, cuyos tripulantes obtuvieron 1.300 pieles en el lapso 1828-31. También al cutter Alonzo, uno de cuyos tripulantes,

forman de hecho y por derecho un estado libre, independiente y soberano, y quedan separados para siempre de la monarquía de España. Lo subrayado es nuestro.

19 The war against the seals. A History of the North American Seal Fishery (McGill-Queen's University Press, Kingston and Montreal, 1985). 
el joven Ansel L. Thomes fue sepultado en la isla Gonzalo en $1832^{20}$. Tan agotadora debió ser la captura que entrados los años de 1840 la faena se redujo notoriamente y tal vez se suspendió por años dada la escasez de animales de piel fina, para reanudarse a menor ritmo en los años de 1870 , motivando la preocupación de la autoridad de la Colonia de Magallanes, debiendo mencionarse a la goleta norteamericana Thomas Hunt hacia 187677 por su recurrente merodeo cinegético en el pequeño archipiélago del mar de Drake.

De esa misma tradición cinegética sobre esos $y$ otros territorios insulares chilenos comenzaron a participar los veleros armados inicialmente por José Nogueira y después por otros empresarios del puerto de Punta Arenas desde fines de los años de 1870 a los de la década siguiente hasta 1892 , época en que se registró la primera prohibición de caza inicialmente por un período de diez años y más tarde indefinidamente. Sin embargo de la manifiesta escasez de animales pelíferos y antes que las autoridades nacionales resolvieran de manera definitiva sobre la prohibición, se conocieron resoluciones de los años 1902, 1903 y 1906 que concedieron el arrendamiento de esas y otras islas para la explotación de los recursos animales en ellas existentes, situación asociada directamente con la génesis del interés antártico de Chile, pero esa es otra historia.

Las concesiones mencionadas no tuvieron destino, bien se sabe, pues el negocio cinegético no era rentable por la virtual extinción de la especie más cotizada. Así y mediando con seguridad más de alguna incursión clandestina en busca de la riqueza que ya no existía, a lo menos en cantidad suficiente, corrieron los años y todo pasó paulatinamente al olvido. Las islas Diego Ramírez fueron prácticamente ignoradas por la gran mayoría de los chilenos de los que dos o tres generaciones de ellos supieron de las mismas en las aulas escolares únicamente como un hecho geográfico casi irrelevante.

Así se llegó al medio siglo XX, época en que la preocupación excepcional de algunos oficiales de la Armada de Chile, de modo particular del talentoso

20 Para 1875 había a lo menos dos tumbas de marineros que habían sido sepultados allí. La correspondiente a Thomes, natural de Portland y fallecido el 30 de septiembre de 1832 a los 19 años de edad, fue relevada por el arqueólogo y visionario contra-almirante Donald Mc Intyre, vio en esos remotos islotes del mar de Drake un apostadero estratégico de cara al inmenso océano antártico y a sus territorios polares que enfrentar a Sudamérica, sobre los cuales la República debía manifestar una presencia soberana activa en servicio de la navegación universal y la humanidad. Se instaló de ese modo en 1953 un destacamento naval -Puesto de Vigía y Señales en la orgánica institucional-, habitado permanentemente, dotado de radiocomunicaciones, para el registro meteorológico, el control de la navegación interoceánica y para el auxilio eventual de alguna nave a su tripulación en caso de que una emergencia lo requiriese.

\section{ISLAS DIEGO RAMÍREZ, UN PATRIMONIO NATURAL EXCEPCIONAL}

Los hermanos Nodal hicieron a Chile un aporte territorial que aunque insignificante en tamaño es importante como posición austral extrema del continente americano en el borde mismo de la plataforma continental, dirigido hacia y enfrentado con el sector antártico situado a más baja latitud en el planeta. La posibilidad de haber sido "un puente" y ser hoy, a lo menos, un resto de tal circunstancia geológica, la intercomunicación entre los actuales dos continentes meridionales, le otorga al pequeño archipiélago un valor excepcional.

En efecto, la noción de ser aún en su exigüidad territorial por su elevada posición latitudinal un ámbito biogeográfico diferente, semejante al de otros territorios insulares extremos situados junto a la invisible frontera de la convergencia antártica, ha llevado el pensamiento y por ende el interés de los estudiosos de las ciencias naturales a la revalorización del archipiélago Diego Ramírez desde un medio siglo atrás hasta el presente, considerándoselo digno de observaciones y estudios especiales para aquilatar su trascendencia como un reservorio natural excepcional $y$, por tanto, como un verdadero patrimonio científico que debe ser conocido y protegido.

Omar R. Ortiz-Troncoso del Instituto de la Patagonia en 1972 (Cfr. nuestro artículo "Cementerios y tumbas rurales de Magallanes", Anales del Instituto de la Patagonia, 23, 5-40, Punta Arenas, 1985 
Si bien fue el geólogo E. Aubert de la Rue quien hizo en 1953 la primera visita que debe calificarse como científica, consideramos que la siguiente realizada a comienzos de 1972 por el botánico Edmundo Pisano del Instituto de la Patagonia (Punta Arenas) debiera fecharse como el principio de la revalorización de las islas Diego Ramírez como un patrimonio natural singular $y$ diferenciado de lo hasta entonces conocido. Esa visita fue motivada por el interés del eminente botánico e investigador, aprovechando las facilidades de transporte brindadas por la Armada de Chile, para hacer un primer reconocimiento fito-ecológico en la isla Gonzalo (sitio del emplazamiento del PVS), como parte de su hacía poco iniciado ambicioso programa de investigación "Determinación de las Regiones Bioecológicas de Magallanes". Los resultados de la visita, colecta de plantas y observaciones entonces efectuadas, permitieron el hallazgo de cuatro especies de plantas vasculares nunca antes conocidas, sobre cuya base Pisano propuso de manera preliminar la creación de una nueva Provincia Biótica que llamó Gramíneo-Turbosa Sub-Antártica ${ }^{21}$. Lo había movido a ello, según relató más tarde, que...Al aproximarse a las islas Diego Ramírez, llama inmediatamente la atención la fisonomía eminentemente herbácea de su vegetación, que contrasta fuertemente con la arbóreo, arborescente y turbosa de las islas australes de la Tierra del Fuego ${ }^{22}$. Se trataba pues, en su cabal entendimiento, de un territorio botánicamente diferente al más cercano geográficamente hacia el norte (islas del Cabo de Hornos), sin embargo de compartir específicamente ambos parte de sus correspondientes floras locales.

Profundizando el estudio, luego de revisar y clasificar nuevas plantas colectadas en la misma isla Gonzalo, en su vecina Bartolomé y en los islotes del sur y norte de ambas con resultado del hallazgo de otras cuatro especies, Pisano pudo verificar años después, en 1981, el grado de afinidad que había entre Diego Ramírez y otras islas subantárticas ${ }^{23}$ y

21 E. Pisano, Observaciones fito-ecológicas en las islas Diego Ramírez, Anales del Instituto de la Patagonia, 3,161169, Punta Arenas, 1972.

22 Id. p. 163

23 South Georgia, Prince Edward, Marion, Macquarie, Crozet, Kerguelen, Heard y Mac Donald, todas de la periferia concordó con los especialistas S. W. Greene y D. W. Walton, que en 1975 habían afirmado la realidad de existencia de una zona botánica subantártica, que en sus límites septentrionales se correspondía con el alcance de la invisible, pero real, línea que determinaba la convergencia antártica ${ }^{24}$. Ese estudio pionero cuyo mérito debe reconocérsele al eminente botánico magallánico fallecido en 1997, aportó los elementos suficientes para la revalorización de las islas Diego Ramírez, ahora bajo la trascendente consideración científica amplia (botánica, zoológica, ecológica, climática, geológica y eventualmente paleontológica, por tratarse de un segmento territorial relicto de una remota conexión gondwánica entre otros territorios subantárticos y antárticos actuales), abriéndose así una posibilidad de investigación y trabajo multidisciplinario. Esta visión inspiradora de una revalorización científica fue recogida y compartida en la época del cambio de siglos, del XX al XXI, por el ecólogo Dr. Ricardo Rozzi, de las universidades de North Texas (EE. UU. de América) y de Magallanes, sirviendo así de fundamento suficiente y sólido para la elaboración y formulación por parte de este especialista del Programa de Conservación Biocultural Subantártica (PCBS), con objetivos varios, el primero de los cuales se concretó en 2005 con la creación de la Reserva de la Biosfera Cabo de Hornos, que hace posible la inclusión para sus propósitos de estudio y conservación de la parte austral del Parque Nacional Alberto De Agostini (Tierra del Fuego) y de la correspondiente al Parque Nacional Cabo de Hornos, ambos los más australes del planeta. Esta disposición a su vez ha definido y define el espacio geográfico terrestre y oceánico terminal de América para su estudio científico completo, determinando desde un comienzo la identificación de sitios prioritarios para la conservación de la biodiversidad de Chile y Sudamérica. Estos sitios prioritarios -hotspots en la terminología científicason de norte a sur el Parque Etnobotánico Omora, inmediato a Puerto Williams en la isla Navarino; la isla Hornos y las islas Diego Ramírez. Los

oceánica de la Antártica.

24 E. Pisano \& Schlatter R. (1981), Vegetación y flora de las islas Diego Ramírez. I. Características y relaciones de la flora vascular. II. Comunidades vegetales vasculares. Anales del Instituto de la Patagonia, 12, 183-204. 


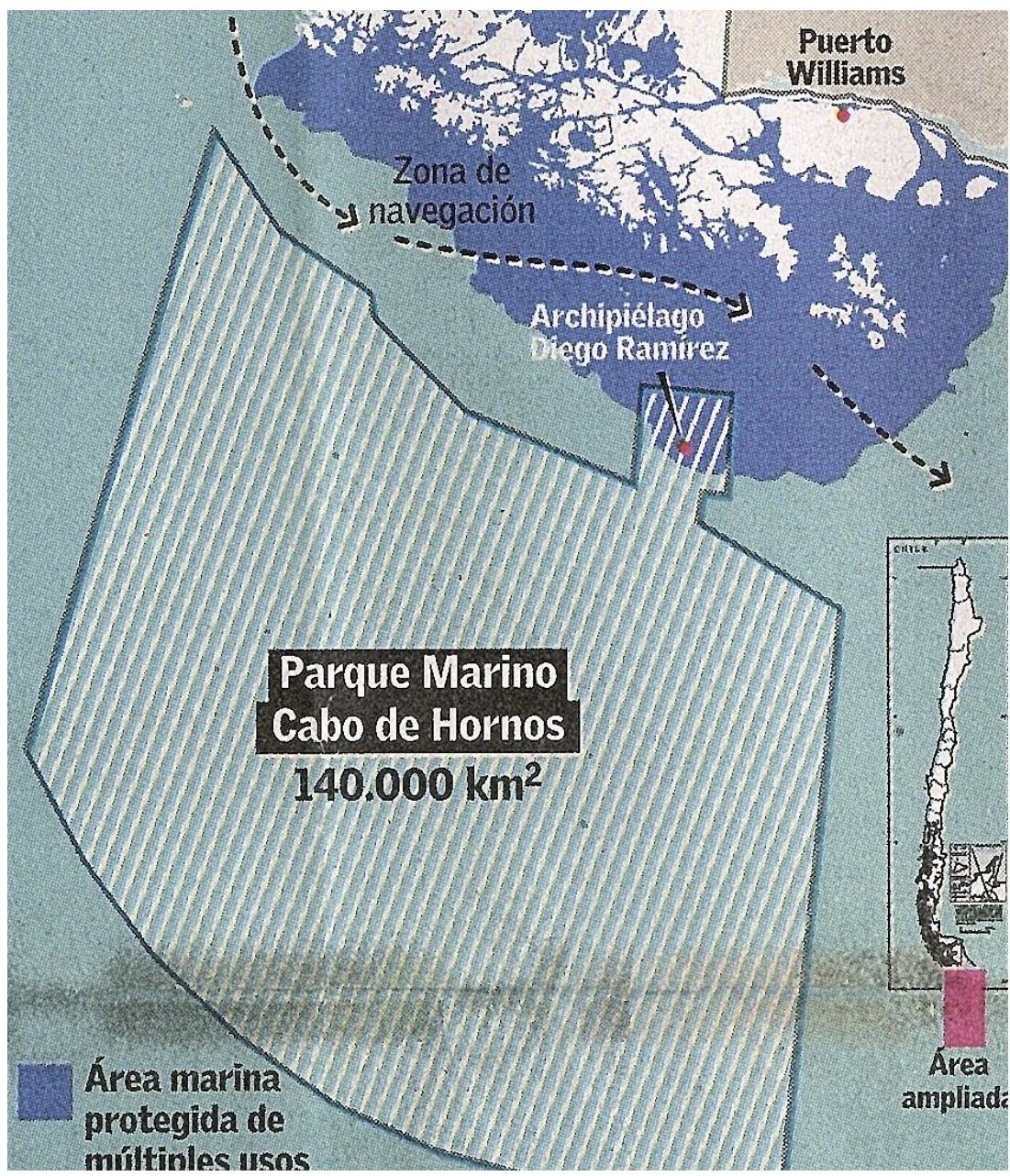

Fig. 4. Mapa sector Cabo de Hornos - paso Drake, región de Magallanes.

primeros estudios y observaciones se encuentran en pleno desarrollo y los mismos adquirirán mayor énfasis y proporción, si cabe, al inaugurarse el Centro Subantártico Cabo de Hornos, en actual construcción en Puerto Williams y que se espera inaugurar en 2020.

Así, pues, para concluir reafirmamos que el hallazgo geográfico de los hermanos Nodal en enero de 1619, las islas Diego Ramírez, cuatro siglos después de ocurrido el hecho puede ser valorado como un verdadero legado patrimonial para la ciencia universal.

\section{AGRADECIMIENTOS}

El autor deja constancia de su agradecimiento a la bibliotecóloga señora Ximena Silva, de la
Universidad de Magallanes, y a la profesora Oriette Sandoval Candia, por su amabilidad y diligencia para ubicar y disponer de información documental y bibliográfica referida a la materia principal del artículo.

\section{BIBLIOGRAFÍA}

Barros Arana, D. (2000). Historia General de Chile, tomo IV. Santiago de Chile: Editorial Universitaria.

Burney, J. (1806). A chronological history of the discoveries in the South Sea or Pacific Ocean. London.

Busch, B. C. (1985). The war against seals. A History of the North American Seal Fishery. McGill-Queen's University Press. Kingston-Montreal.

Gallez, P. (1973). Valentín y sus dos bahías fueguinas. Karukinká Cuaderno Fueguino, 6,17-31. Kroon, P. (Ed.) (2016). 
Atlas of Cape Horn. Bussum.

Martinic B., M. (1974). Crónica de las tierras del sur del canal Beagle. Buenos Aires-Santiago de Chile: Editorial Francisco de Aguirre.

Martinic B., M. (1974). Actividad lobera y ballenera en aguas del litoral de Magallanes y Antártica entre 1868 y 1916. Revista de Estudios del Pacífico, 7, 7-26.

Martinic B., M. (1999). Cartografía Magallánica 15231945. Punta Arenas: Ediciones de la Universidad de Magallanes.

Ovalle, A. (1646). Histórica Relación del Reyno de Chile. Roma.

Pisano, E. (1972). Observaciones fito-ecológicas en las Islas Diego Ramírez. Anales del Instituto de la Patagonia, 3, 161-169.

Pisano, E., \& Schlatter, R. P. (1981). Vegetación y flora de las islas Diego Ramírez. I Características y relaciones de la flora vascular. II Comunidades vegetales vasculares.
Anales del Instituto de la Patagonia, 12, 183-194..

Rosales, D. (1877). Historia General del Reyno de Chile. Flanes Indiano. Valparaíso.

Rozzi, R. (2017). La cumbre austral de América. En Cabo de Hornos. Museo Chileno de Arte Precolombino. Santiago de Chile.

Sin autor (1621). Relación del Viage que por orden de Su magestad y acuerdo de el Real Consejo de Indias, hicieron los capitanes Bartholomé García de Nodal y Gonzalo de Nodal, hermanos, naturales de Pontevedra, al descubrimiento del estrecho nuevo de San Vicente, que hoy es nombrado de Maire, y al reconocimiento del de Magallanes, etc.

Vázquez De Acuña, I. (2004). Historia Naval del Reino de Chile 1520-1826. Síntesis de Ana Victoria Durruty Corral. Compañía Sudamericana de Vapores S.A. Corporación del Patrimonio Cultural de Chile. Santiago. 
